\title{
LA DECONSTRUCCIÓN. FUNDAMENTOS Y POSIBILIDADES DE PROYECCIONES PRÁCTICAS
}

\author{
Rosa Eugenia Montes Doncel \\ Universidad de Extremadura \\ rosamont@unex.es
}

\section{RESUMEN}

La Deconstrucción constituye uno de los capítulos más controvertidos e intrincados de la Teoría Literaria del siglo XX. El presente artículo aspira a elaborar un recorrido útil para el investigador sobre los antecedentes, el desarrollo histórico, el contexto cultural y filosófico y las principales ideas manejadas por esta escuela. Se sintetizan las nociones precursoras de Nietzsche y Heidegger y se exponen los planteamientos de Derrida y su recepción en los autores de la Escuela de Yale: De Man, Hartman, Hillis Miller, Bloom. El trabajo reflexiona acerca de los vínculos entre Filosofía y Teoría de la Literatura y propone una posible aplicación de las oposiciones deconstruccionistas (habla/escritura, presencia/ausencia, centro/margen, etcétera) sobre textos literarios hispánicos.

Palabras Clave: Deconstrucción: antecedentes y desarrollo; Derrida; oposición habla/escritura; oposición presencia/ausencia; oposición centro/margen.

\section{ABSTRACT}

Deconstruction is one of the most controversial and complex chapters of $20^{\text {th }}$-century Literary Theory. This article is an attempt to present a useful review for researchers on the antecedents, historical development, cultural and philosophical contexts and the main ideas dealt with by this school. Nietzsche's and Heidegger's forerunning ideas are 
synthesized, Derrida's approach is exposed, as well as the reception of Deconstruction by the authors of the Yale School: De Man, Hartman, Hillis Miller, Bloom. The essay presents a reflection on the links between Philosophy and Literary Theory, and offers a possible application of the deconstructivist oppositions (speech/writing, presence/absence, centre/margin, etc.) on Hispanic literary texts.

KeY Words: Deconstruction: antecedents and development; opposition speech/ writing; opposition presence/absence; opposition centre/margin.

\section{DeCONSTRUCCIÓN Y FILOSOFÍA. ANTECEDENTES FILOSÓFICOS DEL DECONSTRUCCIONISMO}

Una de las aportaciones más fértiles que nos puede procurar el estudio del Deconstruccionismo reside en marcarnos la pauta para una reflexión sobre los lazos existentes entre Filosofía y Teoría de la Literatura ${ }^{1}$. No es azar que este movimiento asistemático por excelencia nazca cuando lo hace, en la segunda mitad del siglo XX: la Filosofía de la Deconstrucción, fruto de su época, constituye la apoteosis del relativismo que preside el pensamiento del siglo pasado en muchas de sus facetas. Por ello, si bien la estrategia deconstructivista se considera apta para todo tipo de discurso, literario o no literario, y dentro de estos últimos a menudo ha sido acoplada a la poesía romántica inglesa, el procedimiento hallará su mejor molde en textos vanguardistas deliberadamente iconoclastas ${ }^{2}$. Por ejemplo, la pugna con el sistema literario y lingüístico de las obras de la brasileña Clarice Lispector y la gala Hélène Cixous evidencia las aporías de tales sistemas.

Entre los autores que presagian de modo meridiano el advenimiento de la Deconstrucción figura en lugar destacado Nietzsche, gran revulsivo de la metafísica teológica occidental; el filósofo germano deconstruyó el principio de identidad, propugnaba el concepto del hombre como prisionero del lenguaje y la muerte de todos los valores absolutos. Su «hermenéutica de la sospecha» sostenía que ante toda manifestación hay que preguntarse: ¿Qué debe esto ocultar? ¿Qué prejuicio está destinado a promover? ¿Contra qué atenta esto? (Nietzsche, 2001). Cuando más adelante trate de inventariar los puntos nucleares de la Deconstrucción quedarán patentes las relaciones entre éstos y el nihilismo y relativismo nietzscheanos.

La Fenomenología de Husserl por su parte destaca la importancia de la percepción, y el estrato del lector adquirirá un rango copartícipe en la lectura deconstructivista. Heidegger horada la metafísica aseverando que el hombre no es algo dado, una presencia, sino un «poder ser»; el ser no es lo propio de cada ente sino la «diferencia» que media entre ellos: el ser se corresponde con la nada en el sentido de trascendencia del ente. Menciona Heidegger el libre juego del devenir del ente y niega el concepto de verdad unívoca, científica, metafísica (adecuación entre una proposición y una cosa). Prefiere antes hablar de aletheia, la verdad que hay que sacar a flote desde donde permanece escondida. Su filosofía del lenguaje encumbra dentro de éste al no científico (la poesía, la

\footnotetext{
1 Vid. Norris, 1983; Ferraris, 1987; Lynch, 1990; Asensi, 1996; Miller, 1989; Peñalver Gómez, 1990.

2 Vid. Jackson, 1982, y Adamson, 1988.
} 
manifestación de los entes, la oposición a la nulidad del ser). No le interesan las palabras que fijan, sino lo que llama «existenciarios», el prurito del lenguaje por dejar traslucir a los entes, y tales «existenciarios» a menudo se sirven de las metáforas. Para Heidegger existen dos movimientos fundamentales en el lenguaje: el rastreo etimológico que indaga el sentido oculto de las palabras y el empleo de la metáfora. Heidegger habla asimismo de la experiencia de pensar lo que no puede pensarse; el lenguaje no es un instrumento, sino que el hombre pertenece al lenguaje ${ }^{3}$. Tales ideas se vinculan con la «diferencia» derridiana, su desmantelación de las oposiciones y su rechazo hacia los significados fijos y estables.

La Deconstrucción, continuum de la crisis del estructuralismo ${ }^{4}$, también establece alianzas con la Hermenéutica de Gadamer, con el marxismo, con la lingüística, con el concepto de intertextualidad y con la teoría feminista de la literatura, si bien se opone a todas estas corrientes. Roland Barthes, cuya presencia parece gravitar sobre áreas diversas de la Teoría literaria del XX, conoce también una etapa deconstruccionista. En «La muerte del autor» (1968) dice que la literatura es subversiva puesto que se trata de un discurso que se niega a fijar los significados. En «De la obra al texto» habla de la dilación constante del significado que se produce en el texto y que conduce al juego; de la ausencia del padre (autor), de la exigencia de co-autoría al lector y del texto ligado al placer erótico. Respecto a la noción de lectura emanada de S/Z (1970), aquí Barthes refuta la originalidad literaria. Toda obra es intertextual por su permanente reescritura de otros textos; diferencia entre texto «legible», que demanda un lector-consumidor desde un significado cerrado, y texto «escribible», necesitado de un lector-productor por su condición de abierto. Dicotomía paralela establece en El placer del texto entre el «texto de placer» (que se correspondería con el primer polo del binomio anterior), y el «texto de goce» (asociado al lector-productor).

El advenimiento de la Deconstrucción. Derrida y Yale. Las ideas de Derrida: ¿QUÉ DECONSTRUYE LA DECONSTRUCCIÓN? HABLA FRENTE A ESCRITURA. LOS PARES PRESENCIA/AUSENCIA Y DIFFÉRENCE/DIFFÉRANCE

Una vez esbozados pues los antecedentes cumple señalar como gran propulsor a Jacques Derrida, autor francés vinculado al grupo Tel Quel que comienza a publicar sus teorías en los años $60^{5}$. El momento fundacional se sitúa en octubre de 1966, en el Simposio Internacional «Los lenguajes críticos y las ciencias del hombre» que se celebró en el Centro de Johns Hopkins y en el que Derrida pronunció la famosa conferencia «Estructura, signo y juego en el discurso de las ciencias humanas», luego incluida en su libro La escritura y la diferencia. Éste supuso el punto de arranque del desarrollo de la Deconstrucción en la Escuela de Yale - Paul de Man, Hillis Miller, Geoffrey Hartam y Harold Bloom—, que implanta el debate filosófico en predios sobre todo literarios. Aunque

\footnotetext{
3 Vid. Heidegger, 1982 y 1987, y Asensi, 2003.

4 Vid. Macksey y Donato, 1972, y Berman, 1988.

5 Vid. por ejemplo Bennington y Derrida, 1994. Son manuales recomendables para internarse en el páramo deconstructivista los de Norris, 1982; Leitch, 1983; Peretti, 1989, o Glusberg, 1991.
} 
no se trata de un grupo homogéneo sus miembros comparten muchos de sus a priori y publican un libro de conjunto que ha hecho las veces de manifiesto (Deconstruction and Criticism; VVAA, 1979). La Deconstrucción americana conocerá su mayor apogeo en la década de los 70 y los primeros años de los $80^{6}$.

Como subraya Pozuelo Yvancos en el capítulo que dedica en Teoría del lenguaje literario a esta parte de la Historia de la Teoría, llevar a cabo una clasificación y definición de las premisas deconstruccionistas acarrea un contrasentido, puesto que la Deconstrucción no contempla ni clasificaciones ni premisas ni definiciones, ni ofrece un pensamiento organizado. Especifico pues para empezar que el uso de los términos de los que a la fuerza hemos de servirnos resulta a veces impropio en el ámbito en que nos movemos. Por otro lado, realizar la interpretación de un texto desde los principios deconstruccionistas desmiente la propia naturaleza de la Deconstrucción en tanto en cuanto este movimiento niega que un texto pueda ser interpretado. Una interpretación racional es imposible, al decir de Hartman. Interpretar un texto no consiste en buscar su más recto sentido, sino en percatarnos de su continua mise en abyme: según algunos, como Miller (1976), sería inexacto incluso afirmar que los intérpretes «deconstruimos» el texto; el texto contiene en sí mismo su Deconstrucción, el lenguaje se deconstruye a sí mismo con el concurso del universo de las lecturas-escrituras.

Muchas de las aproximaciones a una descripción de la teoría y la crítica deconstructivistas se formulan de hecho via negatione: es más factible enunciar lo que la Deconstrucción no es. Culler en su famoso tratado Sobre la Deconstrucción escribe que

[...] la Deconstrucción no aclara los textos en el sentido tradicional de intentar captar un contenido o tema unitario; investiga el funcionamiento de las oposiciones metafísicas en sus argumentos y los modos en que las figuras y las relaciones textuales [...] producen una lógica doble y aporética (Culler: 99).

Pero apostilla Culler que, en contra de lo que se ha insinuado a veces, la Deconstrucción no consiste en «un proceso de libre asociación de ideas en el que todo vale, aunque sí se concentra en las implicaciones de los conceptos y figuras y no en las intenciones del autor» (99). Sin embargo, atendiendo a los axiomas (o a los «no-axiomas», con perdón del anglicismo) del decálogo derridiano, y tras la experiencia de leer prácticas de Deconstrucción aplicada (y no estoy recurriendo a autores de segunda fila: valga el muy conocido artículo de Hillis Miller «El crítico como anfitrión»), se me antoja difícil hallar un límite trazado para el «todo vale». De hecho, la Deconstrucción carece de límites, tanto en su objeto de estudio como en su metodología. Y así añade el propio $\mathrm{Cu}$ ller más adelante:

La Deconstrucción no tiene una teoría mejor de la verdad. Es una práctica de la lectura y de la escritura armonizada con las aporías que surgen en los intentos de decirnos la verdad. No desarrolla un nuevo marco o solución filosóficos sino que va de un lado a otro, con una ligereza que espera que resulte estratégica [...] (Culler: 138).

\footnotetext{
${ }^{6}$ Vid. Arac, 1983; Martin, 1984; Cederna, 1989.
} 
En palabras de Macaya:

-Por una parte, aparece la doble sesión que, como doble escritura o escritura bifurcada, determina un situarse dentro del sistema, un «inscribirse en él» —con lo cual, implícitamente, se / le afirma - pero con el propósito de subvertirlo desde su mismo interior.

-Y por otra parte se le formula la aporía que, en tanto mecanismo de escape frente a la solución dialéctica — escape frente al recurso de la síntesis que es tradicional en Occidentepropone como respuesta la alternativa insoluble y no sintetizadora, entendida como un «ni lo uno, ni lo otro» frente a cualquier concepto anterior (Macaya: 7. Subrayado mío).

La tarea deconstructiva, por definición, no tiene fin. La estrategia deconstructivista desdeña buscar un objetivo: su único objetivo, si así puede llamársele, está en ella misma, en la ejecución de lo que Derrida llama «protocolos de lectura» o «escritura de la escritura». En definitiva, y usando palabras de Manuel Asensi, «la Deconstrucción no es en rigor ni un análisis ni una crítica» (1990: 57) ${ }^{7}$.

Derrida socava los cimientos platónicos del logocentrismo (Blesa, 1998). El pensador argelino, que prefiere el término «diseminación» al de «Deconstrucción», incide en que la metafísica occidental reputaba al logos, la palabra hablada, comunicación natural y no mediatizada, y origen del lenguaje escrito, su representante, que se entiende artificial e indirecto. El habla era concebida en estrecha ligazón con el significado, mientras que en la escritura las marcas físicas pueden estar divorciadas de la persona que las produjo. La escritura opera por lo común de manera diferida, en ausencia del hablante, y a veces incluso anónimamente, ajena a cualquier autor. En el Fedro Platón condenaba la escritura como forma bastarda de comunicación, separada del padre u origen, en tanto que Rousseau decía que la escritura es un suplemento añadido al habla. Para Derrida, en cambio, el lenguaje escrito no constituye un estadio ancilar respecto a la lengua hablada ensalzada por Platón, Rousseau y por supuesto Saussure. Derrida refuta a Platón cuando éste tacha a la escritura de pharmakon, «veneno», recordando que esta voz también significa «remedio», y que se relaciona con pharmakeus (mago, brujo y prisionero). A las razones de Rousseau replica que la escritura no se podría añadir al habla si el habla fuera una plenitud natural y suficiente, si no contuviese en sí una «ausencia» susceptible de ser completada por un «suplemento».

Para Derrida las características que se atribuyen al habla (y fundamentalmente la polisemia) atañen a todo signo; su «gramatología» erige una propuesta abierta a una teoría general de la escritura. Acuña pues una nueva noción de escritura, la archiescritura o protoescritura: un lugar de producción primaria que origina tanto el habla como el texto escrito. Resume Asensi:

El nuevo concepto de escritura (que evidentemente no es un concepto y que ya no tiene nada que ver con el concepto corriente de escritura) es lo que excede, comprende y precede al lenguaje, su condición de posibilidad, y ya no designa el vehículo de un conjunto de unidades preexistentes en el habla, sino el modo de producción que constituye todas esas unidades: la escritura como esparcimiento, articulación y diferenciación (Asensi, 1990: 42).

7 Vid. también Asensi, 1987, y Gasché, 1979. 
Los signos son el producto de un sistema de diferencias. Saussure cuando hablaba de la forma del contenido ya había explicado que «casa» significa porque se opone a «cata», a «cara» y a «cama», y para Derrida, ciertamente, los signos no se alzan como entidades positivas, sino en tanto efectos de diferencia. Declara Derrida:

El juego de las diferencias supone, en efecto, síntesis y remisiones que prohíben que en ningún momento, en ningún sentido, un elemento simple esté «presente» en sí mismo y no remita más que a sí mismo. Ya sea en el orden del discurso hablado o del discurso escrito, ningún elemento puede funcionar como signo sin remitir a otro elemento que tampoco está simplemente presente. Este encadenamiento hace que cada «elemento» — fonema o grafema— se constituya a partir de la traza que han dejado en él otros elementos de la cadena o del sistema (Derrida, 1972b: 35-36).

Podría argüirse que Derrida no ha hecho más que efectuar un cambio de nomenclatura, que la «diferencia» derridiana y su díptico capital presencia/ausencia corresponden al sistema de oposiciones de Saussure que define el rasgo distintivo, o al fenómeno descrito por Jakobson cuando estudia las relaciones paradigmáticas y el principio de equivalencia del eje de selección sobre el eje de combinación en el discurso literario, o, desde la óptica marxista de Balibar y Macherey, al juego dialéctico entre el contenido manifiesto (lo dicho) y la presencia fantasmagórica del poder (lo no-dicho). Pero por una parte Derrida, aunque indiscutiblemente tributario de la Linguiística de Saussure, labora desde la ausencia y no desde la presencia. Sin embargo este sería también el caso de Macherey y de algunas prácticas de crítica feminista: lo que separa a la oposición deconstruccionista de las oposiciones de otro signo estriba en que la Deconstrucción no subvierte los binomios situando al segundo miembro del par, el habitualmente postergado, por delante del primero (por ejemplo, ausencia sobre presencia, extranjero sobre local), ya que ello equivaldría a instaurar una metafísica nueva, un orden nuevo, una jerarquía nueva, y lo que se recusa es que puedan existir metafísica, orden o jerarquía de ninguna índole. La presencia es inasible, se desplaza, pero eso no significa que la ausencia sea fija. Aquí procede incorporar un contribuyente derridiano conspicuo: el denominado descentralización.

Derrida distingue différence, relativa a la alternancia, a la diferencia; de différance, que en francés se pronunciaría igual (subrayo la querencia del autor por explotar las letras mudas, no perceptibles en el habla), derivada del verbo latino differo: esparcir, diseminar (vid. Adamson, 1993). Cada elemento presente remite a otra cosa distinta de sí mismo, al tiempo que conserva la marca del elemento pasado y se deja ya señalar por la marca de su relación con el futuro. Todo signo difiere, aplaza su significado. Pozuelo explica muy claramente este punto, vinculándolo con la fusión entre centro y margen:

La ausencia de significado trascendental extendió al infinito el campo y el juego de las significaciones. Se ha producido un descentramiento, un sistema sólo de diferencias. Si, como dice Saussure, el significado está en función de las diferencias entre términos y cada término no es sino un nudo de relaciones diferenciales, cada término nos remite a otros términos de los que difiere y con los que guarda una relación. No existe ya el centro u origen del significado, éste está constantemente diferido por el propio sistema de diferencias. No hay otra cosa que discurso, la única presencia es la búsqueda de la ausencia (Pozuelo: 137). 
OTRAS OPOSICIONES DERRIDIANAS: CENTRO/MARGEN, FILOSOFÍA/LITERATURA, AUTOR/LECTOR. LOS CONCEPTOS DE HUELLA, INJERTO, SUPLEMENTO E ITERABILIDAD. LAS EXPANSIONES DE LA DECONSTRUCCIÓN

Han comparecido supra las oposiciones habla/escritura, presencia/ausencia, différence/differánce, y centro/margen (parergon); y estrechamente hermanadas a ellas afloran otras: Filosofía/Literatura; significante/significado; significado/referente; lectura correcta/lectura incorrecta; autor/lector; sobra/adición (suplemento); dentro/fuera (himen); interior/exterior.

Derrida trata el par presencia/ausencia, y su disquisición en torno a él le conducirá a hablar de ausencia de centro y de ausencia de significado. El centro no está presente, no tiene un lugar fijo, se desplaza a los márgenes y los márgenes pueden ocupar su lugar. Esta propuesta desestabiliza por supuesto cualquier concepción de estructura (que implica siempre que la obra está cerrada y posee un centro), del mismo modo que negar la correspondencia entre significado y significante rompe todo paralelo entre la Deconstrucción y los principios de la lingüística sausseriana. De hecho, para Derrida el significado originario o trascendental nunca está presente fuera del sistema de diferencias (señálese cómo se superponen différence y differánce); el signo remite a otros signos, nunca a un significante, y el significante a su vez no evoca un referente exterior al texto, al discurso, por la sencilla razón de que Derrida no admite hiato entre el interior y el exterior.

Este desplazamiento del centro revierte en la práctica de privilegiar lo marginal ${ }^{8}$. Muchos de los trabajos del autor galo toman como base integrantes secundarios de los textos de los pensadores que analiza (una obra menor o poco difundida, un escolio, notas a pie de página), y los elevan a una posición relevante: por ejemplo, «Parergon» nace a partir de un comentario en La crítica del juicio de Kant sobre la ornamentación; «La farmacia de Platón» se apoya en una apreciación acerca de la escritura al final del Fedro. No existe centro, puesto que lo periférico puede devenir centro. Desde un punto de vista técnico, Derrida se siente atraído por el aparte, los entrecomillados, cursivas y guiones en tanto indicios de lo anecdótico, y por el quiasmo como maniobra reveladora de cruce de conceptos $^{9}$. Por supuesto, la primacía de lo marginal enlaza con la dualidad interior/exterior, que gozará de un gran predicamento en el postcolonialismo, y es la espita por la que la Deconstrucción se mezcla con las prédicas de las escuelas postmodernistas que abogan por la revisión del canon.

La inexistencia de margen delimitado sustenta algunas de las ideas deconstruccionistas cardinales: no hay literatura frente a mundo exterior, por lo que el texto remite siempre a sí mismo; no hay significante frente a significado pues todos los significados son a su vez significantes (tropos), con lo cual la Deconstrucción se desmarca también de la crítica temática escorada hacia el contenido (Asensi, 1990: 57-59). No hay lectura correcta versus lectura incorrecta, y no hay oposición entre Filosofía y Literatura (vid. Lacoue-Labarthe) ni entre huella y origen. Pondré el acento en el debate de estas dos últimas cuestiones: el rango del lenguaje crítico como indistinto del literario y la visión deconstruccionista de la «huella»o «injerto» (obviamente asociados a la intertextualidad).

\footnotetext{
${ }^{8}$ Relaciónese esto con el Nuevo Historicismo; vid. Montes Doncel, 2004.

9 Un trabajo reciente de Carreres ilustra sobre la noción derridiana de traducción.
} 
La Deconstrucción, al elevar los textos críticos a la misma categoría de los estéticos, supone un elemento perturbador en la Teoría de la Literatura ${ }^{10}$. Pero para poder hablar de literatura «desde fuera» de la literatura tendría que haber un «fuera» de la literatura, una separación que el modelo deconstruccionista no reconoce. Aduciendo que en la Filosofía y en la Crítica también hay tropos, los textos filosóficos se afrontan con las mismas armas que los tradicionalmente llamados literarios: recordemos en este punto que la Hermenéutica romántica y la Estilística idealista habían igualmente encarecido el estatus del crítico, y pueden compararse los planteamientos deconstruccionistas con la famosa máxima de Lledó según la cual «no hay lugar fuera del lenguaje desde donde pudiéramos mirarlo» (1997: 54); serán pertinentes asimismo las dudas del autor español en torno al desideratum de la objetividad. Remarca Asensi que «el acto inicial, desde Aristóteles, de toda teoría literaria (la delimitación de un interior y un exterior) es deconstruido, diseminado, puesto entre interrogantes» (Asensi, 1990: 31). Para Derrida no hay un «fuera del texto».

La Deconstrucción está más centrada en la crítica de la crítica que en el propio discurso literario. Las mismas obras de Derrida (y en cierta medida las de Barthes) tienen carácter metafilosófico y patentizan la tendencia a fundir creación y crítica: piénsese sobre todo en Glas, escrito a dos columnas, que intercala textos de Jean Genet y de Hegel. Dice De Man:

Al no ser científicos, los textos críticos han de leerse con la misma conciencia de la ambivalencia que se aporta al estudio de los textos literarios no críticos (De Man, 1979: 180).

[...] los textos literarios son ellos mismos críticos, pero ciegos, y la lectura crítica de los críticos intenta deconstruir la ceguera. [...] Lukács, Blanchot, Poulet y Derrida pueden ser denominados, todos ellos, «literarios» [...] a causa de su ceguera y no a pesar de ella. [...] La interpretación no es otra cosa que la posibilidad de equivocarse; proclamando que un cierto grado de ceguera forma parte de la especificidad de toda literatura, hemos reafirmado también que, del texto, depende absolutamente la interpretación, que, de la interpretación, depende absolutamente el texto (De Man, 1979: 215-216).

Mientras otros modelos discutían sobre el método más valedero para acercarse a los textos literarios (y la postmodernidad, más adelante, discutirá cuáles de esos textos son dignos de fijar la atención en ellos, y en virtud de qué criterios ${ }^{11}$ ), la Deconstrucción pone en tela de juicio que haya distinción de esencia entre tales textos y sus interpretaciones. Dinamita pues la frontera que separaba autor de lector. ¿Son los deconstruccionistas inmanentes? De atender a su interés por el lenguaje escrito, al análisis minucioso que emprenden de las palabras del texto, a su concepto relativista del tiempo y a su indiferencia hacia la dimensión biográfica, tendríamos que responder que sí. De Man pondera ante todo los conceptos de tropo y retórica, Miller se concentra en el juego lingüístico y aplica el fenómeno de mise en abyme al lenguaje, y Hartman define la Deconstrucción como una lectura atenta.

${ }^{10}$ Este es un aspecto en que la Deconstrucción se opone frontalmente a la Pragmática y en concreto a Peirce, para quien el mensaje científico se había decantado por una «ética de la terminología» claramente discriminada del lenguaje literario.

11 Para un recorrido por las preocupaciones sobre el canon vid. mi artículo de 2001/2003. 
En cuanto a la negación del par autor/lector, si hay una corriente en cuyo seno triunfe la intentio operis sobre la intentio auctoris es sin duda la Deconstrucción. Para postular la intentio auctoris habría que partir de la posibilidad de un significado estable, unívoco, y con un origen determinado (el acto de poiesis del autor), y esto es justamente todo lo que niega la Deconstrucción. Derrida habla de una absoluta independencia entre los signos escritos y los agentes que los emiten o los perciben (el escritor y el lector), ya que pueden repetirse en otros contextos: es la condición de «iterabilidad», y de ahí dimana que todo signo, para el filósofo francés, sea polisémico. Hartman, hablando en nombre del grupo de Yale, da prioridad al significante, la fuerza de la forma, sobre el significado, y afirma que el lenguaje literario es irreducible al sentido.

La posibilidad de iterabilidad del signo produce [...] su perpetua alteración. De ahí que todo signo sea polisémico. Esta polisemia universal, dictada por la différance, es lo que Derrida denomina diseminación (Peretti: 79).

«La Deconstrucción existe sólo en virtud de la repetición», como asevera Culler, pero, ¿cuál es entonces la postura ante la Historia? Curiosamente, no se podría en puridad calificar de ahistórico al Deconstruccionismo: la Historia forma parte de ese texto global que no posee fronteras. Culler dice que Derrida «deja claro tanto la historicidad de las articulaciones como la imposibilidad de hacer de esa historicidad una base o fundamento» (116); esto es, utiliza la Historia contra la Filosofía y la Filosofía contra la Historia.

No hay huella de un origen, sólo huella de una huella. La huella es un injerto cuyo rastro se pierde; percibir el «intertexto» ayuda a comprender el sentido del texto receptor, porque la intertextualidad se sitúa dentro del marco. El injerto en cambio no: toda huella remite a otra huella y ese proceso no tiene fin. No hay oposición entre extranjero y local dado que todo es local y extranjero a la vez. Así lo expresa Derrida:

[...] cada término es un germen, cada germen es un término. El término, el elemento atómico, engendra dividiéndose, injertando, proliferando. Es una simiente y no un término absoluto. Pero cada germen es su propio término, tiene su término no fuera de sí, sino en sí como su límite interior, formando ángulo con su propia muerte (Derrida, 1972a: 453-454).

Glosa Peretti sobre esta ausencia de márgenes:

El texto es un tejido de textos, un entramado de diferencias diseminado al infinito, indecible, de modo que resulta difícil determinar dónde acaba un texto y dónde empieza otro (164).

El suplemento «suple» una diferencia y al mismo tiempo proporciona algo adicional. No hay cadena de significantes, sino suplementariedad, juego de sustituciones infinitas. Brota la «paleonimia» o cuestión de los «viejos nombres»: la operación del injerto textual provoca unos efectos que impiden la centralidad del texto; la escritura se presta a encadenar un «no-sentido». 


\section{LA ESCUELA DE YALE Y LA NOCIÓN ESTELAR DE MISREADING}

Han salido ya a colación las principales aportaciones de los críticos de Yale: no obstante, si deseamos delimitar más, conviene subrayar las ideas de Paul de Man, acuñador de los provocadores y difundidos conceptos de la «resistencia a la teoría» y la «retórica de la ceguera», y que es quien ofrece sin duda el perfil más interesante del Deconstruccionismo norteamericano y en realidad del Deconstruccionismo en general ${ }^{12}$. De Man elucubra sobre el tropo, el símbolo y la alegoría, y estima que los tropos no son algo que pueda quitarse o añadirse al lenguaje: constituyen su verdadera esencia (De Man 1979: 106). Deudor no sólo de Derrida, sino también de Heidegger y Nietzsche, De Man abunda en la noción de «retoricidad» y concluye que el texto literario es mejor cuanto más polémico.

Asensi resume el pensamiento de Miller, para quien existen dos tipos de crítica:

[...] la metafísica, fundamentada en valores tales como la presencia, la diferencia lenguaje/metalenguaje, la oposición literal/figurado, la idea de una lectura «correcta» (monosémica o polisémica) y «adecuada», y la deconstructiva, cuya estrategia se centra en una afirmación y en una negación de la anterior a través de una escritura que sigue el libre y laberíntico juego del texto (Asensi, 1990: 52).

La propuesta (sería tal vez inadecuado llamarla metodología) de Hillis Miller reposa en tres criterios:

1) la interpretación del texto consiste en seguir el laberinto histórico (una etimología sin valores de origen) que propone el injerto textual y va de «figura en figura, de concepto en concepto, de motivo mítico en motivo mítico, a través de una repetición que de ninguna manera es una parodia»; 2) el crítico debe proceder, para ello, tratando de encontrar el elemento que en el sistema estudiado es alógico y rompe con la unidad de sentido; 3) ahora bien, para Miller eso no significa que se deba deconstruir el texto literario, pues éste se auto-deconstruye a sí mismo sin necesidad de ningún suplemento. El crítico únicamente señala esa «auto-deconstrucción». [...] La Deconstrucción no es el desmantelamiento de una estructura de un texto, sino la demostración de que éste se ha deconstruido ya a sí mismo (Asensi, 1990: 53) ${ }^{13}$.

Hay que señalar que Hartman y Bloom encarnan modelos un tanto heterodoxos dentro de esta Escuela. Hartman antepone significante a significado y hace hincapié en la inexistencia de distinción entre texto original y comentario crítico. «El destino de la lectura» se plantea que la crítica sea una modalidad de creación. En cuanto al Bloom deconstruccionista, cabe decir que la simbología freudiana del efebo y el precursor con la cual él se refiere al poeta y sus modelos poseía ya una antiquísima formulación en el tópico que veía a los escritores como enanos subidos en hombros de gigantes. Habla del «romance de familia», la interpretación fantástica de sus padres que hace el niño. No hay textos, sino sólo

12 Remito a Norris, 1988; Pulido, 1994, y a las obras del propio De Man citadas en el índice bibliográfico. Tanto éstas como las de Bloom, independientemente de las discrepancias cuyo contenido pueda suscitar en el lector de hoy, suelen resultar más accesibles y de lectura mucho más grata que las del críptico Derrida.

13 Vid. también Asensi, 1991. 
relaciones entre textos. Los poetas están «condenados» al diálogo con sus precursores, a formar parte de una colectividad de creadores llenos de amargura. Distingue seis pasos: 1) elección: el poeta nuevo o efebo es atrapado por el poder del poeta antiguo; 2) pacto entre el poeta nuevo y el viejo; 3) rivalidad; 4) encarnación de una visión nueva en el poeta novel; 5) interpretación revaluadora; y 6) resurrección del poeta muerto en el vivo.

La auténtica alusión de un poema a otro anterior se hace por lo que no dice, por lo que reprime. El Bloom del periodo deconstruccionista se apoya en Nietzsche a través de la lectura de éste que llevó a cabo De Man y se centra sobre todo en la cuestión de la misreading ${ }^{14}$.

Todo poema es la interpretación errónea de un poema madre. Un poema no equivale a la superación de la angustia, sino que es esa angustia. Las malas interpretaciones de los poetas o poemas son más drásticas que las malas interpretaciones de los críticos o críticas; pero se trata solamente de una diferencia de grado y no de especie. No hay interpretaciones, sino solamente malas interpretaciones, $y$, por lo tanto, toda crítica es poesía en prosa (Bloom, 1973: 110-111. Subrayado mío).

De otro lado, los tentáculos de la Deconstrucción se han extendido a territorios del psicoanálisis, el marxismo, la antropología, la lingüística y la poética feminista (Kristeva, Starobinski, Ryan, Foucault, Barthes, Lyotard). Para Pozuelo Yvancos la adscripción de la lectura feminista al Deconstruccionismo «es muy discutible y más parece una estrategia editorial del libro de J. Culler [Sobre la Deconstrucción]» ${ }^{15}$; no obstante las contribuciones del Deconstruccionismo han sido tan frecuentemente proyectadas a los estudios de género que merece la pena dedicar una explicación al entronque entre estos dos ámbitos (vid. Montes, 2005). Según Derrida el objetivo de deconstruir las oposiciones es entre otros descubrir lo que la Historia ha ocultado u obstruido, y este supuesto se aproxima mucho al de palimpsesto manejado por Gilbert y Gubar en relación con el discurso femenino y su subversión latente. Leemos en La diseminación:

El espesor del texto se abre de este modo al más allá de un todo, el nulo o absoluto fuera. Por ello su profundidad es a la vez nula e infinita. Infinita porque cada capa cobija otra. La lectura se parece entonces a esas radiografías que descubren, bajo la epidermis de la última pincelada, otro cuadro oculto: del mismo pintor o de otro pintor, poco importa, que, carente de materiales o por buscar un nuevo efecto, habría utilizado la sustancia de una antigua tela o conservado el fragmento de un primer esbozo (Derrida, 1972a: 397).

En el dominio de la crítica feminista Emilia Macaya apostilla y sintetiza muy aclaratoriamente estas ideas del autor francés:

La teoría de la suplementariedad, en relación con la interpretación textual, supone que aquello dejado de lado por parte de quienes anteriormente interpretaron un texto, puede ser aún

${ }^{14}$ Vid. los trabajos de Bloom recogidos en la bibliografía. Para un recorrido y una crítica de la evolución del pensamiento de Bloom vid. Lentricchia.

${ }^{15}$ Pozuelo: 132; en verdad el famoso texto de Culler traza muchos meandros, no siempre justificados, sobre el feminismo o la Recepción, antes de entrar en la materia que se presenta como objeto específico del libro. 
más importante que todo lo demás, precisamente por las razones que mediaron para marginarlo. [...] La desconstrucción de los opuestos, labor en que se empeña primariamente el así llamado «desconstruccionismo» derridiano, consiste ante todo en invertir la jerarquía existente en un momento dado, para hacer evidente la dependencia de un término con respecto del otro (Macaya: 6).

\section{Posibles APLiCACIONES PRÁCTICAS DE LA DECONSTRUCCIÓN}

Puesto que una gran parte de los trabajos de Deconstrucción aplicada se orienta a la poesía romántica, periodo literario en que estaban especializados muchos componentes de la Escuela de Yale ${ }^{16}$, a la hora de realizar ejercicios prácticos me he inclinado por otros flancos. En el citado artículo «El crítico como anfitrión», fácilmente localizable para el lector español por haber sido traducido a nuestro idioma e incorporado en la difundida antología de Manuel Asensi (1990), Hillis Miller proporciona un ejemplo de la proyección de la mise en abyme al lenguaje, de cómo el modelo deconstruccionista exprime todas las posibilidades significativas de cada vocablo buceando en su etimología ${ }^{17}$. Quevedo presenta un caso muy fértil para efectuar un ejercicio de este jaez con el soneto que comienza «Sulquivagante, pretensor de Estolo», de lectura ciertamente abstrusa y al mismo tiempo abierta en virtud del «juego» que ejecuta con las palabras.

\section{Soneto 836 \\ AL MESMO GÓNGORA}

Sulquivagante, pretensor de Estolo, pues que lo expuesto al Noto solificas y obtusas espeluncas comunicas, despecho de las musas a ti solo,

huye, no carpa, de tu Dafne Apolo, surculos slabros de teretes picas, porque con tus perversos damnificas los institutos de su sacro Tolo.

Has acabado aliundo su Parnaso; adulteras la casta poesía, ventilas bandos, niños inquietas,

parco, cerúleo, veterano vaso: piáculos perpetra tu porfía, estuprando neotéricos poetas.

\footnotetext{
${ }^{16}$ Hartman brindaba por ejemplo una lectura de «Al otoño» de Keats en Lectura y creación. Pueden consultarse como obras señeras Bloom, 1974 y De Man, 1984.

${ }_{17}$ Aguiar e Silva (1986) anuncia una lectura deconstruccionista de una autora española, Rosalía de Castro, pero lo cierto es que la interpretación que nos ofrece en este artículo el gran teórico luso no puede considerarse un patrón de análisis deconstructivo.
} 
Podemos ayudarnos con el recorrido etimológico llevado a cabo por Ignacio Arellano (aunque este crítico no supedite desde luego su trabajo a ninguna premisa deconstruccionista). El texto de Quevedo resulta, a la vez que hermético (de ardua exégesis), deliberadamente abierto, puesto que los vocablos, semántica y sobre todo formalmente, sugieren pero no imponen una dirección interpretativa. «Sulquivagante» es una palabra inventada, pero da la sensación de un combinado de «sultán» y «vagante»; tampoco existe el supuesto nombre propio «Estolo», que pareciera aludir a un ente mitológico, pero evoca «estólido» y «estulto». En la órbita habitual del Quevedo satírico Arellano apunta que «surculos», «slabros»y «picas» portan connotaciones sexuales, y menciona a propósito de «surculos» $\mathrm{y}$ «piáculos» el gusto quevedesco por los compuestos de tipo escatológico como «parti-cular», «vin-cular», «culi-seo». En esta parodia (término que sería enojoso para algunos deconstruccionistas) del modus operandi de Góngora, el gran presente-ausente del texto, valdría hablar de injerto recordando los versos 15 y 16 de las Soledades, «del siempre a la montaña opuesto pino / al enemigo Noto». La huella gongorina se aprecia tanto en la elección del tema mitológico como en la factura sintáctica, singularmente en el forzado hipérbaton del segundo cuarteto.

No por muy conocido es menos útil para este propósito el capítulo 68 de Rayuela, escrito en «glíglico» (nombre acuñado por el propio Cortázar), un lenguaje musical que pretende comunicar una impresión por medio del sonido de sus sílabas y su ritmo, propiciando así que cada lector le asigne un sentido. Nadie que lea el pasaje dudará de que en él se describe un encuentro sexual, pero la mayoría de los términos son neologismos ayunos de significado. La plantilla deconstructivista se pliega bien a textos iconoclastas:

Apenas él le amalaba el noema, a ella se le agolpaba el clémiso y caían en hidromurias, en salvajes ambonios, en sustalos exasperantes. Cada vez que él procuraba relamar las incopelusas, se enredaba en un grimado quejumbroso y tenía que envulsionarse de cara al nóvalo, sintiendo cómo poco a poco las arnillas se espejunaban, se iban apeltronando, reduplimiendo, hasta quedar tendido como el trimalciato de ergomanina al que se le han dejado caer unas fílulas de cariaconcia. Y sin embargo era apenas el principio, porque en un momento dado ella se tordulaba los hurgalios, consintiendo en que él aproximara suavemente sus orfelunios. Apenas se entreplumaban, algo como un ulucordio los encrestoriaba, los extrayuxtaba y paramovía, de pronto era el clinón, la esterfurosa convulcante de las mátricas, la jadehollante embocapluvia del orgumio, los esproemios del merpasmo en una sobrehumítica agopausa. ¡Evohé! ¡Evohé! Volposados en la cresta del murelio, se sentían balparamar, perlinos y márulos. Temblaba el troc, se vencían las marioplumas, y todo se resolviraba en un profundo pínice, en niolamas de argutendidas gasas, en carinias casi crueles que los ordopenaban hasta el límite de las gunfias (Cortázar: 533).

Diferentes críticos se han apercibido de la intertextualidad (o «huella», si hemos de emplear nomenclatura exclusivamente deconstruccionista, pues el intertexto conoce otros alcances) de determinados versos del Poema de Mio Cid en el incipit del «Romance de la pena negra». García Lorca escribió 
estructura en que rebrota el «Apriessa cantan los gallos / e quieren quebrar albores» del Cantar de gesta medieval. Pero la metáfora de Lorca es mucho más osada (y más bella): las «piquetas de los gallos» funcionan como sujeto, «la aurora» como complemento directo. En el Poema de Mio Cid el verbo «quieren» no contiene un significado de voluntad; conforma con el infinitivo una perífrasis de incoación que vendría a decir: «están a punto de». «Albores», el equivalente semántico de «aurora», no es el objeto, sino el sujeto pospuesto, en disposición paralela con la cláusula anterior («cantan los gallos»). Sin embargo, para el lector familiarizado con el poema lorquiano, al llegar a este verso le resulta casi imposible no recordar el texto contemporáneo, convertido en nuevo «anfitrión» de tales palabras, y tendemos a leer automáticamente otorgando a los «gallos» la categoría de sujeto no sólo de «cantar», sino también de «querer», confiriendo al verbo «querer» su valor pleno y a «albores» el papel de complemento, en suma convirtiendo en transitiva una oración que no lo era. Esta lectura violentaría el sensus litteralis (en terminología hermenéutica), pero la enorme difusión y el feliz resultado concebido por Lorca, quien tal vez leyó mal el verso, esto es, realizó una productiva misreading, ha condicionado para las futuras generaciones de lectores la recepción de este fragmento del Cantar. ¿Mejora la oración con la nueva lectura? Propicia una solución lograda, y aún más extrañamente original en su contexto histórico. ¿Ha conseguido el «Romance de la pena negra» alterar la comprensión y el significado del texto antecesor? ¿Es legítima la segunda propuesta, que desprecia deliberadamente la intentio auctoris? Desde una perspectiva deconstruccionista tan legítima sería una como otra, y no se postularía definitiva ninguna de las dos: un nuevo anfitrión podría generar una nueva vuelta de tuerca. Si lo más a que puede aspirar el escritor, según el dictum de Bloom (apophrades o retorno de los muertos, la sexta de sus seis razones revisionistas), es a expresarse de tal modo que parezca que es el precursor el que lo imita a él, se diría que Lorca lo ha conseguido. Aunque el hecho en realidad tiene un nombre más sencillo sin necesidad de recurrir a ninguna ratio: emulación.

En cuanto al autor, para Derrida la inscripción del nombre propio en el texto no es más que la firma (que tiene que ser «reiterada» para ser reconocible). Juega con nom propre (nombre propio) y non propre (no propio). El autor no materializa una instancia trascendente, sino que se confunde con el texto que escribe y que le domina. Allego el ejemplo de Cervantes, que en mi opinión sabía muy bien lo que se hacía cuando ensamblaba su nombre en el estrato ficcional, y hacía decir al cura sobre el autor de La Galatea que era «más versado en desdichas que en versos». Véanse estos otros textos del Quijote:

Cautivaron a don Pedro Puertocarrero, general de la Goleta, el cual hizo cuanto fue posible por defender su fuerza y sintió tanto el haberla perdido, que de pesar murió en el camino de Constantinopla, donde le llevaban cautivo. Cautivaron ansimesmo al general del fuerte, que se llamaba Gabrio Cervellón, caballero milanés, grande ingeniero y valentísimo soldado. Murieron en estas dos fuerzas muchas personas de cuenta, de las cuales fue una Pagán de Oria, caballero del hábito de San Juan, de condición generoso, como lo mostró la suma liberalidad que usó con su hermano el famoso Juan Andrea de Oria; y lo que más hizo lastimosa su muerte fue haber muerto a manos de unos alárabes de quien se fió, viendo ya perdido el fuerte, que se ofrecieron de llevarle en hábito de moro a Tabarca, que es un portezuelo o casa que en aquellas riberas tienen los ginoveses que se ejercitan en la pesquería del coral, los cuales alárabes le cortaron la cabeza y se la trujeron al general de la armada turquesca, el cual cumplió con ellos 
nuestro refrán castellano, que «aunque la traición aplace, el traidor se aborrece»; y, así, se dice que mandó el general ahorcar a los que le trujeron el presente, porque no se le habían traído vivo. Entre los cristianos que en el fuerte se perdieron, fue uno llamado don Pedro de Aguilar, natural no sé de qué lugar del Andalucía, el cual había sido alférez en el fuerte, soldado de mucha cuenta y de raro entendimiento; especialmente tenía particular gracia en lo que llaman poesía. Dígolo porque su suerte le trujo a mi galera y a mi banco y a ser esclavo de mi mesmo patrón, y antes que nos partiésemos de aquel puerto hizo este caballero dos sonetos a manera de epitafios, el uno a la Goleta y el otro al fuerte. Y en verdad que los tengo de decir, porque los sé de memoria y creo que antes causarán gusto que pesadumbre (501-502).

Cada día ahorcaba el suyo, empalaba a este, desorejaba aquel, y esto, por tan poca ocasión, y tan sin ella, que los turcos conocían que lo hacía no más de por hacerlo y por ser natural condición suya ser homicida de todo el género humano. Solo libró bien con él un soldado español llamado tal de Saavedra, el cual, con haber hecho cosas que quedarán en la memoria de aquellas gentes por muchos años, y todas por alcanzar libertad, jamás le dio palo, ni se lo mandó dar, ni le dijo mala palabra; y por la menor cosa de muchas que hizo temíamos todos que había de ser empalado, y así lo temió él más de una vez; y si no fuera porque el tiempo no da lugar, yo dijera ahora algo de lo que este soldado hizo, que fuera parte para entreteneros y admiraros harto mejor que con el cuento de mi historia (507).

Como se apunta en nota en la edición de Francisco Rico, el personaje de Pedro de Aguilar citado en el primer fragmento es ficticio, mientras que los otros nombres corresponden a personas reales. Uno y otros reciben empero el mismo tratamiento retórico, como rige en la ficcionalidad literaria para conseguir el effet du réel. Asimismo podemos estudiar el fenómeno de mise en abyme en La ilustre casa de Ramires de Eça de Queirós y preguntarnos si la historia inserta es subsidiaria, está condicionada por la principal, o hasta qué punto sucede al contrario (vid. mi artículo de 2006). En «La noche boca arriba» de Cortázar el extrañamiento proviene de que se nos ha hecho creer que el relato inserto (el sueño, la historia ubicada en la actualidad) era el principal, y el auténtico relato principal (la historia emplazada en la América precolombina) un sueño. Analícese también la idea de Borges de que cada escritor crea sus precedentes, expuesta en «Kafka y sus precursores» (de Otras inquisiciones). La obra del autor argentino recusa -finge recusar- los conceptos de originalidad y propiedad intelectual y del texto en cuanto entidad cerrada.

\section{LOS ENEMIGOS DE LA DECONSTRUCCIÓN}

Se han manifestado contra la Deconstrucción Booth, Abrams (quien previamente fue atacado por Miller), Wellek, Ellis, Steiner, Todorov y Guillén entre otros muchos. Guillén por ejemplo la tilda de neovanguardismo caduco, y Booth y Compagnon dicen que hay que distinguir entre «teoría» y «terroría» ${ }^{18}$. Domínguez Caparrós comenta: «Llama la atención que lo que comenzó como una crítica de las certezas metafísicas acabe en las certezas menos prestigiosas de un dogma» (431). El consenso de semejante nómina de

18 Vid. Booth, 1979; Abrams, 1977; Wellek, 1982; Ellis, 1988; Steiner, 1991; Todorov, 1997; Guillén, 1985; Compagnon, 1998; Felperin, 1985. 
autoridades casi disuade de intentar la defensa del credo deconstruccionista, pero es indiscutible que para bien o para mal esta parcela del pensamiento forma parte de la historia de la teoría y la crítica literarias, y planea en muchos momentos y desde muchos ángulos sobre las distintas zonas de debate del postestructuralismo: el crítico debe inexcusablemente conocerla y familiarizarse con su terminología, siquiera para rebatirla. ¿Qué puede ofrecernos la Deconstrucción? Si lo que perseguimos es comprender mejor el significado de los textos literarios, parece que una corriente que no cree que los textos literarios posean un significado poco tendría que aportar. Humorísticamente el paradigma deconstruccionista podría resumirse en la frase: «De qué se trata, que me opongo». La Deconstrucción niega todo sin proponer a cambio ninguna opción. Pero para poder hablar de extranjero tiene que admitirse el hecho de lo local; para que quepa noción de marco ha de haber un centro. El escepticismo y el relativismo radicales albergan en ellos mismos su refutación lógica, pues cuando no se admite que exista ninguna lectura correcta pierde sentido hablar de lecturas no correctas. Si no existe ningún argumento válido, tampoco podría enarbolarse como válido nada de lo que aporta la Deconstrucción. Sirva el pedestre ejemplo de que aun el reloj que está parado tiene que acertar con la hora exacta por lo menos dos veces al día.

En la praxis del análisis, ¿nos suministra este marco teórico alguna herramienta útil? ¿Llevando a cabo las operaciones derridianas, como hemos hecho, se han iluminado los textos por vías que otros métodos no habrían roturado? ¿Invita la Deconstrucción a reconsiderar nuestros puntos de partida? La aspiración a la objetividad metodológica y el propósito de alcanzar la condición de ciencia empírica que han caracterizado a la mayoría de escuelas lingüísticas del siglo XX es defenestrada por la Deconstrucción, apoteosis de la subjetividad. La teoría antihistoricista por antonomasia nos ayuda, en su radicalidad, a entender el contexto filosófico de relativismo extremo en que se gestó.

\section{BIBLIOGRAFÍA}

Abrams, M. H. (1977): «The Deconstructive Angel», en Critical Inquiry, 3, pp. 425-438.

AdAmson, J. (1988): Wounded Fiction: Modern Poetry and Deconstruction, Nueva York, Garland.

AdAMson, J. (1993): «Deconstruction» y «Différance/différence», en I. R. Makaryk, ed., Encyclopedia of Contemporary Literary Theory. Approaches, Scholars, Terms, Toronto University Press, pp. 25-31 y 534-535.

Aguiar E SiLva, V. M. (1986): «Para uma leitura deconstrutivista da poesia de Rosalía de Castro», en Actas del Congreso Internacional de estudios sobre Rosalía de Castro e o seu tempo, II, Santiago de Compostela, Universidad, pp. 183-191.

ARAC, J., et alii (1983): The Yale Critics: Deconstruction in America, University of Minnesota Press.

Arellano, I. (2002): «El soneto de Quevedo "Sulquivagante, pretensor de Estolo": ensayo de interpretación», en J. Enrique Duarte y V. Roncero López, coords., Quevedo y la crítica a finales del siglo XX (1975-2000), Pamplona, EUNSA, vol. 1, pp. 35-46.

Asensi, M. (1987): Theoría de la lectura. Para una crítica paradójica, Madrid, Hiperión.

AsENSI, M. (1990): «Estudio introductorio: Crítica límite/El límite de la crítica», en ASENSI, M., ed., pp. 9-78. 
AsENSI, M. (1991): «Retórica y Deconstrucción: textos y parásitos en J. Hillis Miller», en VVAA, Retórica: Historia, Teoría y Práctica, Cádiz, Seminario de Teoría de la Literatura, pp. 75-86. AsENSI, M. (1996): Literatura y filosofía, Madrid, Síntesis.

ASENSI, M. (2003): Historia de la Teoría de la Literatura (el siglo XX hasta los años 70), Valencia, Tirant lo Blanch.

AsEnsi, M., ed. (1990): Teoría literaria y Deconstrucción, Madrid, Arco/Libros.

BARTHES, R. (1968): «La muerte del autor», en El susurro del lenguaje. Más allá de la palabra y de la escritura, Barcelona, Paidós, 1987, pp. 65-71.

BARTHES, R. (1970): S/Z, Madrid, Siglo XXI, 1980.

BARTHES, R. (1971): «De la obra al texto», en El susurro del lenguaje. Más allá de la palabra y de la escritura, Barcelona, Paidós, 1987, pp. 73-82.

BARTHES, R. (1974): El placer del texto, Madrid, Siglo XXI.

Bennington, G., y DerRida, J. (1994): Jacques Derrida, Madrid, Cátedra.

Berman, A. (1988), From the New Criticism to Deconstruction. The Reception of Structuralism and Post-structuralism, Urbana, University of Illinois Press.

BlesA, T. (1998): Logofagias. Los trazos del silencio, Zaragoza, Anexos de Tropelías.

Bloom, H. (1973): The Anxiety of Influence. A Theory of Poetry, Nueva York, Oxford University Press. Traducción: La angustia de las influencias, Caracas, Monte Ávila, 1991.

Bloom, H. (1974): Los poetas visionarios del romanticismo inglés, Barcelona, Seix Barral.

BLoom, H. (1975a): A Map of Misreading, Nueva York, Oxford University Press.

Bloom, H. (1975b): Kabbalah and Criticism, Nueva York, Seabury. Traducción: La Cábala y la crítica, Caracas, Monte Ávila, 1992.

Bloom, H. (1976): Poetry and Repression: Revisionism from Blake to Stevens, Yale University Press. Воотн, W. C. (1979): Critical Understanding: the Powers and Limits of Pluralism, University of Chicago Press.

CARRERES, Á. (2005): La retórica de la traducción en Jacques Derrida, Oxford/Berna/Berlín/Frankfurt/Nueva York/Viena, Peter Lang.

Cederna, C. M. (1989): «Derrida e la critica decostruttiva americana», en Lingua e Stile, XXIV, 1, pp. 159-170.

Cervantes, M. de (2004): El Quijote, Barcelona, Galaxia Gutenberg, ed. de Francisco Rico.

Compagnon, A. (1998): Le Demon de la théorie, París, Seuil.

CoRTÁzAr, J. (1984): Rayuela, Madrid, Cátedra, ed. de Andrés Amorós.

CULLER, J. (1982): Sobre la Deconstrucción: teoría y crítica después del estructuralismo, Madrid, Cátedra, 1984.

De MAN, P. (1971): Blindness and Insight. Essays in the Rhetoric of Contemporary Criticism, Nueva York, Oxford University Press. Parcialmente traducido en: «Retórica de la ceguera: Derrida, lector de Rousseau», en ASENSI, M., ed., 1990, pp. 171-216.

De Man, P. (1978): «The Epistemology of Metaphor», en Critical Inquiry, V, pp. 11-19.

De Man, P. (1979): Allegories of Reading: Figural Language in Rousseau, Nietzsche, Rilke and Proust, New Haven, Yale University Press. Traducción española: Alegorías de la lectura. Lenguaje figurado en Rousseau, Nietzsche, Rilke y Proust, Barcelona, Lumen, 1990.

De Man, P. (1984): The Rhetoric of Romanticism, Nueva York, Columbia University Press.

DE MAN, P. (1986): La resistencia a la teoría, Madrid, Visor, 1990.

DERRIDA, J. (1967a): De la gramatología, Buenos Aires, Siglo XXI, 1971.

DERRIDA, J. (1967b), La escritura y la diferencia, Barcelona, Anthropos, 1989.

DERridA, J. (1972a): La diseminación, Madrid, Fundamentos, 1975.

DERridA, J. (1972b): Posiciones, Valencia, Pretextos, 1977.

DERRIDA, J. (1972c): Márgenes de la filosofía, Madrid, Cátedra, 1989.

DerridA, J. (1986): Memorias para Paul De Man, Barcelona, Gedisa. 
DERrida, J. (1990): «Ulises gramófono: El oui-dire de Joyce», en AsENSI, M., ed., pp. 81-134.

Domínguez CAPARRós, J. (2002): «La Deconstrucción», en Teoría de la literatura, Madrid, Editorial Centro de Estudios Ramón Areces, pp. 409-435.

Ellis, J. M. (1988): «What Does Deconstruction Contribute to Theory of Criticism?», en New Literary History, 19, pp. 359-379.

FELPERIN, H. (1985): Beyond Deconstruction. The Uses and Abuses of Literary Theory, Oxford, Clarendon Press.

FERRARIS, M. (1987): «Jacques Derrida. Deconstrucción y ciencias del espíritu», en AsENSI, M., ed., 1990, pp. 339-395.

Gasché, R. (1979): «La Deconstrucción como crítica», en ASENSI, M., ed., 1990, pp. 253-305.

GILBERT, S. M., y GUBAR, S. (1979): La loca del ático. La escritora y la imaginación literaria del siglo XIX, Madrid, Cátedra, Universidad de Valencia e Instituto de la Mujer, 1998.

Glusbeg, J., ed. (1991): Deconstruction. A Student Guide, Londres, Academy Editions.

GUILLÉN, C. (1985): Entre lo uno y lo diverso. Introducción a la literatura comparada (Ayer y hoy), Barcelona, Tusquets, 2005.

HartMAn, G. H. (1975): «El destino de la lectura», en ASENSI, M., ed., 1990, pp. 217-249.

HARTMAN, G. H. (1992): Lectura y creación, Madrid, Tecnos.

HeidegGer, M. (1982): Ser y tiempo, México, Fondo de Cultura Económico.

HeIDEgGer, M. (1987): De camino al habla, Barcelona, Seix Barral.

JACKSON, R. (1982): «The Deconstructed Moment in Modern Poetry», en Contemporary Critics, 23, pp. 306-322.

LACOUE-LABARTHE, Ph. (1970): «La fábula (Literatura y filosofía)», en ASENSI, M., ed., 1990, pp. $135-154$.

LeITCH, V. B. (1983), Deconstructive Criticism. An Advanced Introduction, Londres, Hutchison.

Lentricchia, F. (1990): Después de la Nueva Crítica, Madrid, Visor.

LLEDÓ, E. (1985): «Literatura y crítica filosófica», en J. M. ${ }^{a}$ Díez Borque, ed., Métodos de estudio de la obra literaria, Madrid, Taurus, pp. 419-463. También en J. Domínguez Caparrós, ed.: Hermenéutica, Madrid, Arco/Libros, 1997, pp. 21-57.

LYNCH, E. (1990): «Exorcismos textuales (sobre la Deconstrucción)», en El merodeador. Tentativas sobre filosofía y literatura, Barcelona, Anagrama, pp. 77-100.

Macaya, E. (1992): Cuando estalla el silencio. Para una lectura femenina de textos hispánicos, San José, Universidad de Costa Rica.

Macksey, R., y Donato, E., eds. (1972): Los lenguajes críticos y las ciencias del hombre. Controversia estructuralista, Barcelona, Barral.

Martin, W. (1984): «La Deconstrucción en América», en Los Cuadernos del Norte, 26, julio-agosto, pp. 36-45.

MilleR, J. H. (1976): «Stevens' Rock and Criticism, as a Cure, II», en Georgia Review, XXX, 2, pp. 330-348.

MilleR, J. H. (1977): «The Critic as Host», en Critical Inquiry, 3, pp. 439-447. Traducción: «El crítico como anfitrión», en ASENSI, M. ed., pp. 157-170.

MilleR, J. H. (1989): «The Function of Literary Theory at The Present Time», en R. Cohen, ed., The Future of Literary Theory, Nueva York, Routledge, pp. 102-111.

MONTES DONCEL, R. E. (2001/2003): «En torno al canon. (Ortodoxos frente a aperturistas y el estado de una cuestión polémica: la crítica literaria de la postmodernidad)», en Tropelías. Revista de Teoría de la Literatura y Literatura Comparada, 12-14, pp. 327-346.

Montes Doncel, R. E. (2004): «De nuevas sobre el Nuevo Historicismo», en Anuario de estudios filológicos, XXVII, pp. 207-219.

Montes Doncel, R. E. (2005): «Aportaciones a la crítica feminista», en Káñina. Revista de artes y letras de la Universidad de Costa Rica, XXIX/1, pp. 89-109. 
Montes Doncel, R. E. (2006): «Proceso de mise en abîme y parodia de la novela histórica en $A$ ilustre casa de Ramires de Eça de Queirós», en 1616. Revista de la Sociedad Española de Literatura General y Comparada, XII, pp. 205-215.

NiETZSChE, F. (2001): Aurora, Madrid, Edaf.

NorRIs, C. (1982): Deconstruction. Theory and Practice, Londres, Methuen.

NorRIs, C. (1983): The Deconstructive Turn. Essays in the Rhetoric of Philosophy, Londres, Methuen.

NorRIS, C. (1988): Paul de Man. Deconstruction and the Critique of Aesthetic Ideology, Nueva York, Routledge.

PeIRCE, Ch. S. (1931/1935): Collected Papers of Charles Sanders Pierce, ed. de C. Hartshorne, P. Weiss y A. Burks, Cambridge, Harvard University Press, 6 vols.

PeÑalver Gómez, P. (1990): La Deconstrucción. Escritura y filosofía, Barcelona, Montesinos.

PeretTI, C. de (1989): Jacques Derrida: texto y Deconstrucción, Barcelona, Anthropos.

Pozuelo-Yvancos, J. M. (1988): «La Deconstrucción», en Teoría del lenguaje literario, Madrid, Cátedra, 1994, pp. 128-158.

Pulido TiRAdD, G. (1994): «Memorias y biografía intelectual de Paul de Man: el discurso derridiano», en Autobiografía en España, un balance: actas del congreso internacional celebrado en la Facultad de Filología de Córdoba del 25 al 27 de octubre de 2001, Universidad de Córdoba, pp. 577-588.

Quevedo, F. de (1999): Obra poética, Madrid, Castalia, ed. de J. M. Blecua, 3 vols.

RYAN, M. (1982): Marxism and Deconstruction: A Critical Articulation, Baltimore, Johns Hopkins University Press.

SteIner, G. (1991): Presencias reales. ¿Hay algo en lo que decimos?, Barcelona, Destino.

Todorov, T. (1997): El hombre desplazado, Madrid, Taurus, 2008.

VVAA (1979): Deconstruction and Criticism, Nueva York, The Seabury Press.

Wellek, R. (1982): The Attack on Literature and Other Essays, Brighton, The Harvest Press and The University of Carolina Press. 